\title{
AS PRÁTICAS DE LAZER DOS MORADORES NAS RUAS DA VILA HOLÂNDIA
}

Recebido em: 22/10/2015

Aceito em: 14/05/2016

Carolina Gontijo Lopes

Universidade de Coimbra

Coimbra - Portugal

Sílvia Cristina Franco Amaral

Universidade Estadual de Campinas

Campinas - SP - Brasil

RESUMO: Este estudo investigou as práticas de lazer na rua dos moradores do bairro residencial Vila Holândia, Campinas, São Paulo, com o objetivo de compreende os usos cotidianos do espaço urbano. Metodologicamente optamos pela observação de cunho etnográfico. Identificamos que a vida comunitária na Vila Holândia passou por profundas transformações sociais. Mesmo assim, ainda encontramos evidências que permitem dizer que a riqueza das experiências da rua ainda resiste ao processo de urbanização das cidades que sucumbem às relações comunitárias mais tradicionais. Nas experiências da rua, os sujeitos compartilham o espaço público e materializam a convivência social. É pelas relações de troca, evitação e conflito que os moradores se apropriam das ruas e das práticas de lazer, estabelecendo as regras e os rituais próprios da identidade social desse lugar. Concomitantemente, a convergência entre os círculos sociais dos diferentes grupos etários na participação em práticas de lazer, no cotidiano da rua, pode garantir a perpetuação dessas formas de apropriação, ao fortificar o pertencimento à sociabilidade para as próximas gerações. São comuns a prática das caminhadas, as brincadeiras de rua, o futebol, a contemplação e o bate papo, que permitem criar certos círculos de pertencimento. Mas, há também discursos que vem a rua como um lugar inseguro, do qual não se sentem pertinentes e pertencentes.

PALAVRAS-CHAVE: Atividades de lazer. Área Urbana. Cidades.

\section{STREET LEISURE PRATICES OF THE RESIDENTS OF NEYBORHOOD OF VILA HOLÂNDIA}

ABSTRACT: This study investigated street leisure practices of the residents of Vila Holandia, a periphery neighbourhood in Campinas, São Paulo state. The aim of the present research was to understand the everyday uses of urban space. Methodologically we opted for ethnographic observation. We found that community life in Vila Holândia underwent profound social transformations. Still, we find evidence that allow to say that rich street experiences resist, while other cities more traditional community relations succumb facing the urbanization process. In the street experiences, subjects share the public space and materialize social coexistence. It is through the exchange relations, avoidance and conflict that residents take ownership of streets and leisure practices, 
establishing rules and rituals of social identity peculiar of this place. Concomitantly, the convergence between social circles of different age groups in leisure activities participation can guarantee the perpetuation of these forms of ownership and strengthen belonging in the street everyday sociability to the next generations. The most common leisure practices in Vila Holândia are walks, children games, soccer, contemplation and chatting creating belonging circles, but there are also talks about the street as an unsafe place, which does not feel it as a relevant space or promotes belonging.

KEYWORDS: Leisure Activities. Urban Area. Cities.

\section{Introdução}

Este estudo investigou as práticas de lazer na rua dos moradores do bairro residencial Vila Holândia, Campinas, São Paulo, com o objetivo de compreende os usos cotidianos do espaço urbano.

Ao questionarmos os problemas decorrentes da urbanização defrontamos com a complexidade da vida cotidiana nos bairros residenciais da periferia urbana. Estes envolvem questões de segurança, mobilidade espacial e humana, acesso à educação, saúde e lazer, bem como a relação de vizinhança e associações de moradores. Mesmo existindo semelhanças entre os bairros periféricos, entendemos que cada local tem suas especificidades. O diálogo com Santos (1998, 2008), Lefebvre (2008) e Fortuna (1997) reforça a compreensão de que o espaço urbano é uma produção social e cultural, que se reconfigura constantemente em meio à intervenção dos sujeitos.

Para Magnani (2012) a cidade é um lugar complexo onde “[...] em vez da anomia, isolamento ou fragmentação, o que se vê são regularidades, arranjos coletivos, oportunidades e espaços de trocas e encontros (MAGNANI, 2012, p. 251)”. Este viés direcionou a cartografia social e cultural do espaço investigativo, as ruas e o entorno da Vila Holândia. E ainda, a identificação de como e por que os sujeitos, moradores, usam a rua para práticas de lazer, e o "outro", aqueles que não usam e por fim, a interpretação das regras e símbolos presentes nas formas de "sociação" nessas práticas que ressignificam o espaço. A interlocução que realizamos ao interpretar a rua, os sujeitos, o 
outro, as práticas de lazer e as formas de sociação identificou que a aprendizagem situada (LAVE e WENGER, 1991) envolve e possibilita as relações comunitárias intergeracionais e entre vizinhos.

A Vila Holândia faz parte do subdistrito de Barão Geraldo na cidade de Campinas, São Paulo. Este agrupamento humano iniciou com a produção de cana de açúcar na chamada Fazenda Rio das Pedras, nos princípios do século XVIII. Com o fim dessa estrutura patriarcal ocorreu o loteamento da fazenda e a comercialização dos seus lotes pelo processo de transição do rural para o urbano. Na atualidade, além dessas mudanças no plano urbanístico, a configuração desse bairro envolve de um lado, a permanência de famílias pertencentes à história da aristocracia canavieira na Vila Holândia, e do outro, a chegada de novos moradores com outras trajetórias e práticas.

Em específico, delimitamos dois problemas dessa periferia urbana para orientar o estudo, são eles: a crescente especulação imobiliária associada ao consumo de fetiches na vida cotidiana; e, a visibilidade da sociabilidade na rua no contexto multicultural e residencial relacionada à insegurança social. Com o foco analítico nas minúcias culturais do cotidiano, buscamos na pesquisa identificar e interpretar os significados das práticas de lazer nas ruas da Vila Holândia.

As práticas de lazer no cotidiano dos moradores foram interpretadas considerando as maneiras de fazer, que Certeau (2014) denomina de “[...] operações cotidianas táticas e estratégicas". A teoria das práticas da abordagem de Certeau possibilita identificar como tática as microresistências que ocorrem em determinadas ocasiões. São processos de desvios das regras dominantes que na perspectiva macro observam apenas a obediência e uniformização. Tal perspectiva do contexto "micro" nos permitiu significar o lazer local dos moradores no bairro, sem, para tanto, descartar as questões macro estruturais. 
O estudo dialoga com Fortuna $(2012)^{1}$ pelo desafio epistêmico e político de reelaborar o conhecimento produzido sobre as cidades latino-americanas. Em tornar visíveis espaços sociais, sujeitos e práticas esquecidas pelo domínio hegemônico da produção do conhecimento do Norte. As formas de resistência estabelecidas em práticas cotidianas (CERTEAU, 2014) entre vizinhos em um bairro, são um exemplo que cada vez mais, são apagadas frente à ascensão das imagens de fragmentação social e individualidade nas cidades do Sul.

Adotamos a observação de cunho etnográfico nas ruas como a principal fonte de informações. Além das impressões escritas no diário de campo, os dados dos questionários e das entrevistas de história oral realizados por pesquisa da qual esta é parte integrante também auxiliaram a investigação do cotidiano na rua. A imersão na Vila Holândia envolveu a nossa circulação pelas ruas do bairro e do seu entorno, a permanência em pontos mais significativos das ruas e a aproximação e conversas com diferentes moradores. A aproximação inicial definiu o período das observações para os turnos diários após o trabalho, as férias escolares, os feriados e os finais de semana em horários diversificados. A escolha desta temporalidade corresponde à delimitação dos períodos de maior frequência dos sujeitos nas ruas. As orientações de etnografia urbana de Magnani (2002) e DaMatta (1991) possibilitaram familiarizar e estranhar as ruas, as práticas, os sujeitos e ainda, identificar seus condicionantes internos e externos respectivamente.

Paralelamente, pelos encontros desses moradores, pelas conversas entre vizinhos, pelas brincadeiras, sobretudo entre as crianças, definimos as práticas a serem observadas. Dentre os encontros, destacamos principalmente aqueles que envolvem as relações de convívio entre idosas, homens frequentadores do bar e crianças, e

\footnotetext{
1 Fortuna, Carlos (2012) "In Praise of other views: The world of cities and the social sciences" Iberoamericana (Berlim), 45, 137 -153.
} 
ocasionam na formação de círculos sociais em determinados espaços da rua. Por convivência entendemos a relação com o coletivo em que os sujeitos renunciam parte da individualidade para tornar possível a vida cotidiana (CERTEAU, 2014), no qual os círculos sociais seriam uma de suas formas. São formas de associações em que os sujeitos não apenas convivem, mas também se reconhecem e são reconhecidos pela identidade individual e coletiva produzida. Os vínculos estabelecidos entre os mesmos fruem em torno de um interesse comum (SIMMEL, 1986).

Por essas combinações, rompemos com o olhar polarizado, privado e público, para interpretar as transições no espaço da rua, na dinâmica de bairro, demarcadas pelos aspectos simbólicos do uso. Os diferentes usos da rua definirão que as formas de apropriação do espaço permitem a transição dinâmica do espaço privado para o público, e do espaço público para o privado (DAMATTA, 1991; CERTEAU, 2009). Esse processo é relativo, pois são os moradores que, ao "sociarem" e se apropriarem dos espaços, reinventam a construção subjetiva da finalidade privada e pública dos espaços de que iremos tratar. Para tanto, a referência estrutural, estabelecida principalmente pela dinâmica econômica que diferencia a propriedade privada dos espaços públicos, será entendida para localizar as condições sociais dos moradores.

\section{A Cidade, o Bairro e as Ruas: O Lugar da Vila Holândia}

A cidade como produto da interlocução entre as dimensões culturais, sociais e econômicas configura espaços urbanos dinâmicos e conflitivos. Estes tensos espaços concebem experiências cotidianas distintas, de acordo com a localização no território da cidade em que os habitantes moram e circulam. O plano urbanístico e acesso aos serviços públicos difere, por exemplo, entre bairro residencial e zonas comerciais, bairro periférico e bairro central, bairros antigos e zonas com condomínios privados. Olhar de 
maneira mais minuciosa as ruas da Vila Holândia enuncia reflexões acerca de questões urbanas de áreas residenciais e periféricas, como: insegurança, mobilidade, pobreza, acesso a educação e lazer, conflitos e convívio entre moradores. As ruas da Vila Holândia foram cartografadas delineando e discutindo a cidade, o subdistrito, o entorno do bairro e o bairro as quais pertencem.

A cidade não é uma coisa. Ela reconhece-se simultaneamente como real e representacional, como texto e como contexto, como ética e como estética, como espaço e como tempo, socialmente vividos e (re)construídos (FORTUNA, 1997, p.4).

A Vila Holândia é um bairro localizado na periferia do subdistrito de Barão Geraldo, da cidade de Campinas, como referido anteriormente. Este bairro recentemente passou por um intenso processo de transformação motivado especialmente pelo avanço da exploração imobiliária. Hoje o bairro está cercado de loteamentos abertos com características privadas, ou seja, que possuem segurança 24 horas por dia e no qual as ruas, embora qualquer um possa circular não são espaços realmente públicos no qual se possa fazer qualquer atividade sem que estes garantidores da ordem venham questionar e até mesmo expulsar. Além disto, foram autorizados e construídos pelo menos oito condomínios fechados no entorno, o que de certa foram tornaram a Vila Holândia uma ilha.

"Não se trata simplesmente de um lugar de passagem e circulação (LEFEBVRE, 1999, p. 27)." "É o lugar do encontro" no qual "efetua-se o movimento, a mistura, sem os quais não há vida urbana, mas separação, segregação estipulada e imobilizada" a rua é informativa, simbólica e lúdica.

As ruas são expressões da vida urbana que estruturam mapas, definem limites entre território, orientam a organização espacial da cidade e ainda, pode ser o “[...] lugar do encontro" (LEFEBVRE, 2008, p.27). Ao mesmo tempo que a definimos como via, trilho ou caminho, que permitem a circulação de pessoas e/ou veículos de um ponto a 
outro, vamos considerar também suas formas simbólicas de interação conformando o modo de vida dos moradores Vila Holândia.

A rua é um lugar significativo de sociabilidade quando apropriada pelos sujeitos no tempo livre para suas práticas de lazer. Foi possível perceber isto ao olharmos os usos das ruas, do bar, da igreja e da associação de moradores e dos arredores, pelos moradores da Vila Holândia. Enquanto espaço urbano, a rua passa por um processo de ressignificação pela presença das conversas entre vizinhos, pelas brincadeiras, sobretudo entre as crianças. Seus moradores, por meio dos encontros, estabelecem pontos na própria rua para realizar determinadas práticas de lazer. Dentre os encontros, destacamos principalmente aqueles que envolvem as relações de convívio social entre idosos, homens frequentadores do bar e crianças. Será pelas relações de troca, evitação e conflitos (SANTOS; VOGEL e MELLO, 1985) que trataremos as formas de sociabilidade entre os moradores que no tempo livre se apropriam da rua pelas práticas de lazer, bem como os espaços do entorno, como a Escola, o Clube e o Centro Cultural Casarão do Barão.

A rua não somente é significativa para tais moradores pela identificação de tais interações no espaço, como também subverte a ideia dela como local de violência, insegurança e medo para lugar de resistência social e cultural. Nesse sentindo, Azevedo e Silva (1999) argumentam que a rua representa espaços das manifestações culturais, das tensões e dos conflitos sociais. Decorrentes desse processo subjetivo, os significados das dimensões simbólicas presentes nas formas de sociabilidade local vão definir as ruas observadas.

DaMatta (1991) afirma que a rua é uma esfera de significação social, representando um espaço transitório e problemático. Os espaços transitórios são parte da 
estrutura social envolvida por "espaços e temporalidades" e permitem mudanças na própria vida do local.

Sendo as cidades as "concretizações de modelos culturais, que materializam momentos históricos e comportam conflitos e conjugações de formas diversas" (SANTOS; VOGEL e MELLO, 1985, p. 7), veremos que as ruas representam algumas tendências das formas recentes de urbanização. Nesse sentido, ao conceber o espaço urbano como em constante mudança (LEFEBVRE, 2008), a rua corresponde a esta realidade.

Na lógica organizacional tratada por Dupas (2005), os incluídos são os moradores dos condomínios e os excluídos são os moradores de fora dos condomínios, ou seja, aqueles que, em sua maioria, não possuem o mesmo poder de consumo dos incluídos para adquirir os serviços privados. E o outro pode ser visto como inimigo nos espaços aos quais não é pertencente. Os incluídos, moradores de condomínios, têm acesso aos serviços de saúde, educação, transporte, lazer e outros ofertados para seu consumo. Os excluídos, grande parte dos moradores da Vila, não têm acesso a esses serviços privados devido ao seu baixo poder aquisitivo e, assim, ficam à deriva da oferta ou da falta de serviços públicos.

Concebemos que a maior parte da ocupação territorial dessa região é composta por condomínios privados e, para atender a demanda desses moradores, os incluídos, visualizamos vários anúncios publicitários para a venda de serviços privados. Enquanto os excluídos, imersos nesse espaço de consumo de serviços luxuosos, apresentam certo desdém pelos serviços públicos recebidos, talvez até mesmo devido ao convívio com a outra realidade. Paralelamente, o próprio serviço público apresenta sua peculiaridade, pois há uma demanda reduzida nesse território por serviços públicos. A tensão é estabelecida pela diferença do poder de consumo entre os moradores. Esse processo de 
ocupação do espaço intensifica a fragmentação entre os diferentes, incluídos e excluídos, e nos impelem a ver a Vila Holândia e suas formas sociais como uma ilha em meio à especulação imobiliária e seus adereços nesse território.

A imersão na perspectiva de perto e de dentro nas ruas da Vila Holândia ocorreu ao entrarmos nas suas ruas, ao circularmos de carro ou de bicicleta, ao andarmos pelos paralelepípedos da via não asfaltada, enquanto permanecíamos sentados na calçada e/ou conversávamos com os diferentes "nativos" (MALINOVISKI, 1997). Isto nos permitiu redefinir os excluídos como moradores, vizinhos e pertencentes, que possuem regras e rituais próprios nas suas relações sociais cotidianas.

A descoberta da experiência da rua (MAGNANI, 1993) permitiu tê-la como lugar e suporte de sociabilidade. A rua, pelas relações e vínculos entre pessoas e espaços, passa a ser um lugar. Lugar, pois incluímos na nossa descrição as interações simbólicas desses moradores com o espaço e observamos a apropriação da rua pelos mesmos (POL e MORANTA, 2005).

A Vila Holândia deixa de ser ilha na perspectiva da experiência da rua e passa a ser vista como um lugar. Este será compreendido, considerando-se o processo de territorialização do distrito de Barão Geraldo, Campinas, São Paulo, que inclui principalmente o crescimento da especulação imobiliária. Assim, imergirmos nas profundas diferenciações ao longo de sua história. Os traços definidores da antiga fazenda de cana de açúcar passaram por mudanças, principalmente nas relações sociais entre os moradores. Ainda florescem na memória dos moradores mais antigos, por meio de seus relatos, os serviços forçosos prestados pelos seus antepassados ao proprietário da antiga fazenda de cana. Relatam também a participação nas festas, nas brincadeiras de rua e no canavial e ainda exprimem uma tristeza ao lembrar que $o$ "[...] que era 
canavial havia se transformado em condomínios" (DIÁRIO DE CAMPO, 17 de maio de 2009).

Parte desses moradores permanece nesse território e perpetuam até os dias de hoje a história vivida pelas gerações anteriores. Corroboramos com DaMatta (1991) ao entender que a memória é marcada pela intensidade das relações estabelecidas. Alguns moradores carregam em sua memória rancores dos conflitos nas relações de trabalho estabelecidas naquele período entre o (s) proprietário (s) da fazenda e seus empregados. Contrapondo-se a esse sentimento, outros carregam lembranças nostálgicas das festas e das experiências coletivas na Vila Holândia.

As relações sociais passadas e conflitantes estabelecem e influenciam as formas de sociabilidade e de apropriação entre os moradores na atualidade. Elas perpassam a rua, bem como a Associação de moradores estagnada, o Centro Cultural Casarão do Barão, os centros religiosos, o bar, a Escola pública e os projetos sociais esportivos do Clube da Rhodia. Essas relações e esses espaços ajudam a explicar e a significar algumas formas como os moradores se relacionam e convivem com a rua.

As três ruas analisadas são a Caieiras, a Cerquilho e a Servidão. A Caieiras e a Cerquilho são as duas ruas paralelas e unidas pela Servidão. O percurso dessas ruas em formato de U, é dotado de paralelepípedos, enquanto a continuação da Servidão em Servidão 1 e 2 é formada de ruas de terra batida.

O percurso em formato de $U$ apresenta calçadas construídas de forma desigual em frente de todas as casas, que serão aqui tratadas como espaços de transição entre a casa e a rua, além de serem propícias ao encontro dos vizinhos. A parte da Servidão não tem essa delimitação entre a casa e a rua. Existe apenas um muro ou uma cerca. Esses três espaços, rua, casa e calçada, de forma descritiva, são definidos, respectivamente, como público, privado e intermediário, de acordo com a ideia de DaMatta (1991). 
Nesse sentido, Santos; Vogel e Mello (1985) têm a rua como o espaço aberto e de uso coletivo para todos os moradores. A casa é o espaço fechado e de uso mais privativo da família e amigos. Já as calçadas são de uso coletivo do público, mas são entendidas como extensão da casa. Por este construto, de acordo com a identidade individual e coletiva relativa ao espaço, as regras e rituais e os comportamentos dos sujeitos são condicionados pelas suas relações cotidianas. $\mathrm{O}$ comportamento dos sujeitos na rua é estabelecido pelo convívio com o coletivo formado nesse lugar.

Todas as ruas são atendidas pelo serviço público básico de energia elétrica, saneamento da rede de esgoto, coleta de lixo, transporte público e Correios. Apenas os moradores da Servidão não asfaltada não têm a mesma facilidade de acesso a todos os serviços públicos, como, por exemplo, ao transporte coletivo, que não passa nessa rua. Esse percorre na Vila o trecho em formato de U. Assim, os moradores precisam pegar o ônibus na Cerquilho, fazendo uma caminhada bem curta, mas que é dificultada nos períodos de chuva e pela noite devido ao barro das ruas não asfaltadas e a ineficiente iluminação local.

O serviço público de transporte coletivo é um fator de conflitos locais, pois o coletivo da rua, que seria atendido por esse serviço, tem opiniões contraditórias sobre o seu trajeto na Vila. Ao mesmo tempo em que há moradores favoráveis a entrada do ônibus na Vila, há outros contra. Uma moradora da Cerquilho demonstra ser favorável à entrada do ônibus na Vila ao comentar que a proposta desse percurso do ônibus teve influência de seu marido. Outro morador pondera posição contrária, “[...] não achou um fato positivo por ter crianças na rua e também porque disse que o ônibus passa muitas vezes em alta velocidade" (DIÁRIO DE CAMPO, dia 16 de abril de 2009).

O espaço não asfaltado foi concebido como território rural, não somente pelas ruas de terra batida, mas pelas configurações das propriedades privadas. Em grande 
parte, são chácaras delimitadas por cercas lisas ou de arame farpado, além de possuírem pequena criação de animais, como vacas, galinhas e outros. Também são contornadas pela mata e cortadas pela ramificação do Ribeirão Anhumas.

A iluminação pública das ruas ainda é composta por alguns postes de luz com estruturas de madeira. A instalação foi resultante da própria organização dos moradores mais antigos. Um morador da Cerquilho afirma que “[...] os paralelepípedos, os postes e a iluminação da rua Cerquilho foram financiadas pelos próprios moradores" (DIÁRIO DE CAMPO, 17 de maio de 2009). Tal fato corrobora com nossa afirmação de que a Vila parece ser ignorada pelo poder público. O poder público tanto não implantou como ainda não fez reformas nesses serviços públicos, enquanto, na Estrada da Rhodia e no loteamento aberto em frente à Vila, mesmo este sendo mais recente, as melhorias já são visíveis e com boa qualidade.

As três ruas observadas, Caieiras, Cerquilho e Servidão podem ser consideradas, relativamente à realidade das cidades atualmente, como espaços arborizados. A distribuição das árvores não é equânime, mas existem árvores em algumas calçadas e essas contribuem com sombras para as mesmas e para parte das ruas. As sombras são destacadas por observar que nelas ocorrem os encontros entre os moradores que permanecem sob elas em dias muito quentes.

Existem lotes que possuem apenas uma casa e lotes que possuem várias casas menores Contabilizamos aproximadamente 90 lotes, distribuídos de forma bem irregular, ou seja, o loteamento do bairro não tem distribuição por metragem igualitária. Os lotes apresentam tamanhos diversificados, bem como número de residências diferente.

Pelas formas de moradias que compõem a Vila Holândia, podemos destacar a diferenciação socioeconômica entre os moradores, tendo desde chácaras para encontros 
sociais até república de homens adultos, empregados temporariamente na construção civil dos arredores. As casas apresentam tamanhos e construções bem diversificadas, sendo a maioria construída de forma horizontalizada, apenas duas ou três possuem dois andares. Parte das habitações são casas em construções que nunca foram concluídas, com tijolos à vista, sem reboco, ou sem pintura, ou sem telha na laje e ainda com material de obras exposto ao tempo. E, mesmo essas, são utilizadas como moradia independentemente da falta de acabamento e da estrutura de segurança oferecida por muros e portões.

Outra característica das casas da Vila Holândia, que se sobressai, são as estruturas de segurança privada, que diferem entre as residências. Existem casas com cerca elétrica, com muros altos, com portões eletrônicos e com interfones, enquanto outras não têm muros, ficam com portões abertos e destrancados, além das próprias portas das casas que raramente são trancadas com chaves. Essas diferenças de estrutura de segurança também são identificadas nos relatos dos moradores. Uns defendem a necessidade de melhoria de segurança e outros afirmam que a casa sem portão e aberta noite e dia “[...] não representa perigo" (DIÁRIO DE CAMPO, 22 de maio de 2009). Para esses, a segurança de suas casas é confiada pelas relações estabelecidas entre os moradores, pelas formas de sociabilidade entre eles, que não sucumbiu à insegurança própria das habitações nos centros urbanos. Pelos mais diferentes relatos, entendemos que existem posições contrárias quanto à segurança na Vila Holândia e essas interferem nas interações entre os moradores.

As formas de transporte público e a localização, cercada por condomínios e sua especificidade na segurança das casas, reforça a ideia da Vila como uma ilha. Um lugar que possui suas especificidades bem distintas do território onde está inserida. Uma ilha que mantém uma rede básica de sociabilidade (MAGNANI, 1996) por envolver suas 
próprias formas de segurança, a sociabilidade entre vizinhos e a perpetuação da história local de geração em geração, diferindo dos arredores.

Para completar a descrição das ruas, adentramos na identificação dos sujeitos que as utilizam, o que nos possibilitará a construção do lugar das práticas de lazer nelas. O ponto principal identificado nessa relação é que a maioria dos moradores representa aqueles que já usaram da rua e ainda usam. Essas duas representações, utilizava antigamente e utiliza atualmente, indicam um montante acima da representação que nunca utilizou. Assim, ao buscar compreender as relações que fruem na rua esse percentual indica que a maioria já se aproximou da rua, logo os conflitos entre os que usam e que não usam estão imersos nessa realidade.

$\mathrm{Na}$ Cerquilho, usam a rua pessoas idosas no período da manhã e, no final da tarde, para iniciar suas caminhadas e conversar com vizinhos. No início da noite, um ou outro jovem fica sentado na calçada em frente de sua casa para conversar com amigos ou namorar. As poucas crianças que vão à rua para brincar ficam em frente de suas casas, nas calçadas e não mantêm uma frequência desse hábito. Alguns moradores da Cerquilho vão para a Caieiras por se identificarem mais com as práticas sociais que lá ocorrem, um morador comentou também que naquela rua havia "mais velhos e adultos" (referindo-se à Cerquilho), e que essa última (referindo a Caieiras) "é mais animada que a dele” (DIÁRIO DE CAMPO, 17 de maio de 2009). Nessa rua, o único espaço específico de sociabilidade dos moradores é a Associação, que está estagnada por conflitos entre os mesmos.

Na Caieiras, no período de nossas observações, o movimento era bem diversificado, incluindo crianças, jovens, adultos e idosos nos diferentes períodos e dias da semana. As crianças que usam a Rua Caieiras para brincar são aquelas que se encontram e ficam na rua, calçadas, casas de amigos, loteamento, pasto, campo, clube e 
outros espaços, nos mais diversos horários, em todos os dias, faça chuva ou sol. Há outras crianças que se restringem a usar da rua plenamente, ficam nas calçadas em frente suas casas, muitas vezes com as mães olhando, ou dentro da casa de amigos em horários mais limitados e com pouca frequência.

Os jovens que passam ou permanecem na Caieiras aparecem mais ao final da tarde e ao anoitecer para conversar entre eles e, muitas vezes, permanecem nas calçadas, no bar ou na Igreja, aos sábados. Entretanto, não têm uma frequência certa de permanência e encontro com amigos na rua. Há uma diferenciação bastante grande dos usos da rua entre os sexos. A maioria é do sexo masculino e se reúne em frente de um bar ali existente. As adolescentes circulam pela rua, permanecem na calçada e nas casas umas das outras. Muitas vezes, elas andam com os irmãos mais novos, para cuidar deles, enquanto os seus responsáveis estão trabalhando.

Os adultos usam da rua principalmente para encontrar vizinhos e conversar. Seus horários e tempo de permanência variam de acordo com o dia da semana. Notamos que aos finais de semana se intensificava a presença deles na rua, mas condicionada principalmente pelo calendário e clima. Alguns se sentam nas calçadas e observam as crianças, tanto mulheres como homens. Outros se encontram e permanecem na esquina do bar, a maioria homens e, principalmente, no final do dia e nos finais de semana.

Já os idosos se encontram com seus vizinhos nos diferentes períodos e independentemente do dia da semana. Pela manhã, alguns, principalmente do sexo feminino, se encontram para fazer caminhada. Apenas verificamos que, aos sábados, no horário da missa na Igreja, o encontro dos idosos compreendia número maior e entre ambos os sexos. Nos outros dias, eram duplas ou trios femininos. Há, ainda, aqueles que observam o movimento da rua pela varanda e do portão de suas casas, mas não costumam ficar nas calçadas e na rua até mesmo pela dificuldade de mobilidade. 
Saímos da visão dos moradores na rua e passamos a olhá-los como parte das casas que estão na Vila, para tanto lembramos que cada casa tem sua particularidade nas formas de sociabilidade familiar ou doméstica. As casas da Vila são compostas das mais diversas configurações domésticas. São muitas as famílias compostas por moradores antigos, outras são compostas de moradores recentes e ainda existem casas em que os moradores não são famílias e, muitas vezes, estão de passagem pela Vila, como a república de homens que moram juntos para trabalhar em obras na região, o que pode representar certa mobilidade desses moradores. Têm ainda casas em que mora apenas uma pessoa e casas/chácaras em que não mora ninguém e são usadas pelos proprietários para práticas de lazer aos finais de semana, feriados e férias.

\section{Usos da Rua: Apropriação, Sociabilidade e as Redefinições do Espaço}

As formas de uso do tempo livre na Vila perpassam pela apropriação da rua e das práticas sociais, considerando que essas são decorrentes da sociabilidade entre os moradores que representa seu potencial simbólico nas formas de interagir. O processo de identificação das práticas de lazer cotidianas permeou a categorização das práticas em pertinentes e impertinentes. Dentro do processo relativo de tornar próprio, apropriar, e que nem sempre é adequado às expectativas do outro (SMOLKA, 2000). Certos moradores se associam e marcam seu "pedaço" (MAGNANI,1996) na rua, tornando seu aquele espaço e aquela prática, entretanto, nesse processo, aparecem diferentes tensões com o outro, principalmente entre os que usam da rua e aqueles que não a usam.

Atualmente, são rotineiras, entre os moradores da Vila Holândia, algumas práticas de lazer, como os jogos de futebol aos domingos, as brincadeiras das crianças na rua, as caminhadas dos idosos, as conversas entre vizinhos nas calçadas, a realização do jogo de bingo e o encontro no bar. Elas acontecem pelo fluxo diversificado dos 
moradores, que apresentam diferenças de sexos, idades, além da rua onde moram, às vezes apresentando certa permeabilidade, como o que foi observado no encontro dos moradores no entorno do bar, em determinados dias. Esse encontro é permitido a mulheres e crianças, mas ele pertence cotidianamente aos homens adultos e é uma prática pertinente e adequada àquele pedaço. Há também quem ache tal prática impertinente e inadequada à vida do bairro.

Ao nos aproximarmos de cada prática, fomos identificando que algumas materializam formas de sociação entre os moradores por se agruparem em unidades, círculos sociais, pela identidade individual e coletiva (SIMMEL, 1986). Pelos círculos compreendemos as interações dos integrantes nas formas de apropriação da rua e das práticas em que se envolvem, buscamos entender por que alguns estão compreendidos e outros não, ou seja, por que para alguns é pertinente e para outros é impertinente. Por que algumas crianças brincam na rua e se sociam nela e outras não? Por que alguns homens se encontram no entorno do bar e se sociam e outros não? Por que alguns idosos conversam com seus vizinhos e outros não?

A análise de espaços deve levar em conta as atividades que se dão nos seus diversos recortes. Assim como a rua é a forma de utilizá-la, o espaço é o uso que permite. Os significados que um determinado suporte material (esquina, calçada, quintal, rua, etc.) pode assumir, resultam da sua conjugação com uma atividade e mudam de acordo com ela. Falamos de espaços e do que pode acontecer, gramaticalmente, em cada um. E o que pode acontecer varia. Mas, na variação mesma dos eventos possíveis, existe uma estrutura que torna o espaço apenas mais uma dimensão social (SANTOS; VOGEL e MELLO, 1985, p. 48).

É pelas formas de sociação e pela apropriação que iremos redefinir a rua o sentido de privado e público. Entrando na Caieiras e na Cerquilho, encontramos uma grande diferença no uso da rua pelos moradores. Na Caieiras, há formas mais diversificadas do que na Cerquilho, desde o número maior de moradores que 
permanecem na rua até ao uso por moradores de diferentes faixas etárias. Essa diferença decorre de questões como os conflitos entre moradores na Rua Cerquilho, quando funcionava a Associação de moradores. O processo culminou na estagnação da associação e no rompimento de relação entre moradores da própria Cerquilho com os da Caieiras. Também há relatos de que a chegada de novos moradores na Vila Holândia repercutiu a sensação de insegurança e, diante disso, alguns moradores da Cerquilho evitam permanecer na rua.

Entretanto, é bom lembrar que a Rua Cerquilho tem um número menor de moradores, um número menor de crianças e um grande número de idosos e adultos. $\mathrm{O}$ grupo etário de adultos merece destaque pela pouca presença na rua devido aos vínculos empregatícios. Assim, compreendemos que a Cerquilho não é apropriada pelos moradores como acontece na Caieiras, pois além das questões de conflitos e segurança, os moradores são distintos com relação a faixa etária e compromissos sociais, por exemplo. É mais visível na Cerquilho o sentimento de impertinência e impróprio que o de pertinência e próprio quanto ao uso da rua.

$\mathrm{Na}$ Cerquilho, existe o encontro entre as senhoras para começarem suas caminhadas. Elas, em dupla ou trio, se encontram nas calçadas pela manhã ou ao final da tarde e vão caminhar ao redor da Vila Holândia. Muitas vezes, andam nas ruas do loteamento que existe em frente e na área chamada Tancão. As senhoras da Cerquilho também se encontram no Centro Cultural Casarão do Barão para participarem das aulas de ginástica gratuita, ofertadas pela psicóloga do Posto de Saúde de Barão Geraldo ${ }^{2}$. E algumas frequentam a Igreja Católica localizada na Caieiras, mas há alguns idosos da Cerquilho que a frequentam.

\footnotetext{
${ }^{2}$ As práticas corporais que ocorrem no casarão foram descritas e discutidas no capítulo: "O Casarão do Barão como espaço para o tempo livre na Vila Holândia".
} 
As idosas da Caieiras também se encontram para as caminhadas e para participar da ginástica no Centro Cultural Casarão do Barão. A diferença que vimos entre as idosas da Caieiras e as da Cerquilho é que as da Caieiras, além das práticas em comum com as da rua Cerquilho, ainda, em grande parte, se apropriam da rua ao interagir, conversando com seus vizinhos e observando as crianças, ou seja, mantendo interações no espaço coletivo da rua, usufruindo no encontro da sociabilidade decorrente dele. Elas, ainda, representam a maioria dos idosos na Igreja Católica. Nesse sentido, saliento que a responsável pela manutenção da Igreja mora na Caieiras, o que facilita o maior uso desses moradores que pertencem ao mesmo grupo social. Os vínculos decorrentes dessas interações possibilitam ao agrupamento dessas idosas não somente apropriar-se da rua, como das práticas que fazem nela. Essas experiências da rua parecem se adequar às expectativas dos outros moradores.

Nessa rua, alguns idosos com maior dificuldade de locomoção ficam nas varandas de suas casas quando o tempo está bom, sem chuva e com sol suave. Eles apenas observam a rua e não interagem muito com as pessoas que circulam. Mas permanecem a observar a Rua Caieiras, pois esta possui um fluxo de sujeitos circulando que pode viabilizar outras formas de distração para eles.

As idosas de ambas as ruas que fazem essas práticas, as conversas nas calçadas, a caminhada, a ginástica do centro cultural e o convívio na Igreja Católica, na sua maioria, são moradoras antigas e conhecem umas às outras. Entretanto, algumas mantêm relações de vizinhança, algumas se evitam e outras estabelecem conflitos (SANTOS; VOGEL e MELLO, 1985). Segundo os autores:

[...] quando nos defrontamos com um outro, três, e somente três coisas podem ter lugar. Ou trocamos algo com ele, ou evitamos fazê-lo de parceiro nessa operação, ou entramos em conflito. Em todos os acasos, operamos com regras e por meio de rituais. $\mathrm{Na}$ troca reforçamos o contato; na evitação procuramos neutralizá-lo; no 
conflito recusamos determinadas condições de uma troca possível. Troca, evitação e conflito vão sempre juntas. São termos virtuais de qualquer relação social e como tais serão considerados (SANTOS; VOGEL e MELLO, 1985, p. 84).

As relações de vizinhança entre os idosos que permeiam a história de convivência entre os moradores é um processo dinâmico, em que a troca, a evitação e o conflito estiveram presentes e, muitas vezes, uma forma sucumbiu à outra. Tal fato fortaleceu transformações nas regras e nos rituais da rua que repercutiram na apropriação desta e nas práticas de lazer das próximas gerações. Ao passar a ver a rua como lugar inseguro, como (im) próprio para seus netos, algumas idosas pertencentes ao grupo que não se apropria da rua criam novas regras e rituais para aquele espaço e para a relação entre vizinhos. Essas regras e rituais também podem enfraquecer os vínculos entre os moradores e minimizar as formas de sociabilidade na rua. Podemos dizer que esse círculo social, idosas que não usam da rua e interagem entre elas, é potencializador da fragmentação das relações comunitárias na Vila Holândia.

Imersos nas transformações, estão os adultos de ambas as ruas. Alguns trazem em sua narrativa recordações das festas comunitárias na Vila e das relações de troca entre vizinhos. Hoje, na Cerquilho, é praticamente impossível encontrar os adultos na rua, caracterizando muito mais a evitação, que a troca e os conflitos na convivência nesse espaço. Os conflitos e trocas na Cequilho estão presentes nos relatos dos moradores, mas não em seu cotidiano. Parte dos moradores da Cerquilho não se relaciona com os moradores da Caieiras por considerar que as formas de apropriação não são adequadas as suas expectativas. Enunciam que, por exemplo, o uso do bar pelos homens pode ser um fator que aumenta a insegurança devido ao consumo de álcool e drogas.

Já na Caieiras, a troca, a evitação e os conflitos são relações visíveis na própria rua. Há alguns moradores que mantêm neutralidade na rua, pois apenas os vimos nas 
suas calçadas quando iam colocar o lixo, atender o portão e sair com seus carros. Essa relação de evitação com os outros moradores e com as práticas sociais na rua de certos moradores ficou evidente quando conversamos com uma moradora, não frequentadora da rua, e ela nos informou o desconhecimento de ruas de lazer ${ }^{3}$ em frente a sua casa. Fato esse relacionado à neutralidade nas formas de contato dessa com os outros moradores.

Geralmente, os adultos que se apropriam da rua estabelecem trocas entres eles. Suas famílias mantêm vínculos afetivos e esses formam círculos sociais entre si. Apesar de identificar diferentes práticas deles na rua, como a interação das crianças, o tomar sol nas calçadas em dias frios, o encontro entre vizinhos depois do trabalho, as conversas entre famílias nas calçadas e o encontro do bar depois do futebol de domingo entre homens, mulheres e crianças, delimitaremos para este escrito nosso olhar aos adultos homens que se encontram no entorno do bar.

O círculo social agrupado por esses sujeitos se forma no entorno do bar. Não vão a este local com a intenção apenas de tomar cerveja ou pinga. Vimos que, em diferentes momentos, eles não estavam bebendo. Em determinados dias, há alguns que bebem, mas não é a identidade desse coletivo se reunir próximo ao bar para beber. Também observamos que, às vezes, estão na calçada do bar para apenas usufruir da sombra das árvores em dias quentes, bem como ficam em frente ao bar, na calçada oposta, em dias frios para se aquecer. E, especificamente aos domingos, é frequente o encontro deles nesse local antes e depois do jogo de futebol, que ocorre fora da Vila. Essa esquina é o ponto deles na rua. Durante toda nossa permanência na observação, eles se encontravam nesse espaço e marcavam seu "pedaço" (MAGNANI, 1996).

\footnotetext{
${ }^{3}$ Houve um período em que um projeto de extensão da Unicamp proporcionava ao bairro ruas de lazer. 
Pelos relatos a seguir, consideramos as contradições sobre os sentidos desse “pedaço" (MAGNANI, 1996), para posteriormente compreender o porquê de eles ficarem nesse local. Certo morador da Caieiras, que usualmente vai para esse ponto para encontrar os outros moradores e estabelece relações de trocas, nos deu um relato que enseja a ideia de adequação e pertinência. Sendo morador recente, diz que buscou fazer parte desse grupo para conseguir bicos e trabalhos. Em alguns momentos, ele recebeu indicação para trabalhar ao se relacionar nesse ponto de encontro. Em contraposição, ao conversar com o proprietário do bar, encontramos outras intenções do grupo.

No primeiro momento, falou que esses rapazes ficam ali para fumar maconha, depois falou que era para apenas conversar depois do trabalho. Achamos que ele ficou um pouco ressabiado em falar que esse local, em frente ao bar dele, era local em que alguns homens fumam maconha, por isso fez questão de afirmar que eram boas pessoas, não são vagabundos, não roubam e trabalham. Ficam ali todos os dias ao final de tarde, incluindo e principalmente aos sábados e domingos. Esses também tomam uma cervejinha e conversam entre eles. Para afirmar mais ainda que não era um encontro maléfico, disse que sua filha e outros parentes também ficavam ali, mas não fumavam. Disse que elas gostam de ficar ali e nem por isso fumam (DIÁRIO DE CAMPO, 04 de abril de 2011).

O ponto de encontro acima apresenta formas distintas de significados dados pelos moradores, viabilizando relações de troca, evitação e conflitos entre os mesmos. Parte dos moradores da Cerquilho não frequenta a Rua Caieiras devido à existência do bar e das pessoas que ali permanecem e das práticas que ocorrem. Na própria Caieiras, também há moradores que compartilham dessa ideia. Eles, que são o outro, relativo ao círculo social formado ao redor do bar, têm esse ponto como uma referência maléfica, (im) pertinente, inadequada, para a Vila.

Esse círculo social formado no entorno do bar é propulsor da maioria dos conflitos entre os moradores adultos e idosos que usam e não usam da rua atualmente. A diferença é que os moradores que usam da rua, mesmo não fazendo parte desse círculo, 
não veem esse encontro como propulsor de violência. Em contrapartida, aqueles que não usam da rua, ou seja, não interagem na rua e nem frequentam o "pedaço" (MAGNANI, 1996) delimitado por esse círculo, são os que o consideram como potencializador de insegurança, ou seja, inadequado para a Vila.

O processo de delimitação desse "pedaço" (MAGNANI, 1996) possibilitou compreender porque o outro não participa dessa prática de lazer. Como falamos anteriormente, para o outro os significados desse encontro são (im) pertinentes por ser, segundo esses, potencializador de violência na Vila. A compreensão do porquê de esses homens se apropriaram desse espaço e dessa prática, formando um agrupamento social, depende de uma multiplicidade de ponderações que configuram principalmente o masculino no cotidiano da Vila.

Para tais ponderações, consideramos de suma importância identificar que quem realizou as observações daquele espaço foi uma pesquisadora mulher. Essa delimitação, em certos momentos, ocasionou o que Santos; Vogel e Mello (1985) nos alertavam, ou seja, que não era permitido a sua entrada nesse círculo de homens no entorno do bar. Nesses momentos, mesmo tendo alguns meses de imersão naquela rua, a pesquisadora representava uma mulher que tem, para esse grupo e nessa temporalidade, determinado significado. Assim, a aproximação nesse “pedaço" (MAGNANI, 1996) somente se deu quando ele era ocupado pela diversidade dos moradores, homens, mulheres e crianças.

O entorno desse bar parece fortalecer a representação masculina desse agrupamento. Estabelecer vínculos no entorno do bar para esse grupo de homens significa potencializar a masculinidade dos mesmos. A construção histórica, social e cultural do estabelecimento do bar na Vila traduz este como ponto de homens, não excluindo o interesse pelo consumo de cerveja e de pinga, e até mesmo drogas, pelos integrantes desse agrupamento. Entretanto, consideramos que as relações de trocas e as 
interações entre os integrantes, condicionadas a uma multiplicidade de fatores, tem o sentido de criar a identidade masculina nesse lugar, na Vila Holândia.

Dentre outros fatores observados que fazem esses sujeitos se reunirem depois do trabalho todos os dias e aos finais de semana, está a conversa pela conversa. Encontrar os amigos, soltar boas risadas, contar e ouvir as histórias, essas trocas os motivam. A própria condição de desemprego de alguns e o alcoolismo de outros são também motivações para se agrupar nesse círculo no entorno do bar.

A tensão é consolidada pelos conflitos entre os moradores devido aos diferentes significados das interações dos sujeitos e avança influenciando a identidade coletiva das formas de se apropriarem da rua e suas práticas de lazer, principalmente pela presente organização familiar na Vila Holândia, que influência no uso das ruas pelos jovens e crianças. Assim, concordamos com Santos; Vogel e Mello (1985) que as pessoas participam das atividades na rua porque elas se conhecem, e aqueles que não se conhecem, os outros, não participam disso, como também não têm condições de compreender as formas que são estabelecidas ali, permanecendo como estranhos ao convívio entre moradores nas ruas da Vila Holândia.

Nas calçadas da Cerquilho, os jovens conversam e namoram em frente as suas casas, principalmente ao entardecer, com pouca frequência e em número bem reduzido. $\mathrm{Na}$ Caieiras, a rua é o espaço de transitar de uma casa para outra pelas moças jovens. As calçadas são tidas por elas como lugar de conversas, namoro e, ainda, nelas, elas aproveitam para esquentar o corpo em dias frios em que o sol está presente, assim como, ao contrário, aproveitam para se refrescar nas sombras das calçadas em dias em que suas casas estão mais quentes que a rua. Jovens frequentam a igreja aos sábados, outros cuidam dos irmãos mais novos, alguns vão, em certos momentos, ao entorno do bar. Em ambas as ruas, observamos que os jovens não possuem uma organização social 
e não mantêm determinada frequência ou rotina em suas práticas na rua. Eles não apresentaram formas de apropriação, tanto da rua como das práticas sociais.

Alguns jovens e adultos do sexo masculino passavam pela rua de carro, de motos ou em cavalos, expondo e mostrando seus pertences de locomoção. Alguns paravam e permaneciam em frente o bar, sempre ao lado do seu pertence. Muitas vezes, ligavam música alta nos seus carros estacionados na rua. Essa prática representa o processo de amadurecimento desses jovens, que procuram mostrar isso aos outros. Todas as vezes em que circularam pela rua com seus veículos, procuraram, ao ligar a música em volume alto ou ao andar em alta velocidade, ter a atenção dos outros moradores.

Enquanto para os jovens isso tem um significado simbólico, para os moradores que usam de outras formas a rua e para aqueles que não a usam tem outro. Portanto, essa ação desencadeia relações conflituosas entre eles e os jovens, principalmente pelo significado de insegurança para as crianças que lá brincam.

As crianças também usam as ruas para realizar suas brincadeiras, assim como os jovens. Algumas delas formam um agrupamento social de crianças na Vila Holândia. Esse agrupamento ocupa casas, calçadas, as ruas e seus arredores, como o pasto, o loteamento, o Centro Cultural, o campo de futebol e o Clube da Rhodia, e não se fixam em determinada calçada ou ponto da rua. Transitam sem se preocupar com os automóveis, cavalos e outros meios que circulam e também não se preocupam se são ou não observadas. Não se preocupam com o espaço que a calçada ocupa em frente às casas e as questões privadas de uso do mesmo.

Elas participam das práticas de lazer na rua por fazerem parte de famílias que consideram o uso da rua pertinente e próprio. São elas que nos permitirão realizarmos as 
redefinições de público e privado, de acordo com o uso e com a apropriação do espaço devido a essas formas de transitar pela Vila.

Elas transitam sem a preocupação em abrir ou fechar a porta, como se não tivessem saído de casa ou entrado. As crianças ao descartarem nesse trânsito entre casa, espaço de uso privado, e rua, espaço de uso coletivo, os cumprimentos de entrada e saída, "oi, como vai e tchau", promovem a privatização da rua pelo uso do seu grupo ou tornam pública sua casa. "Diríamos que, quanto mais às portas se abrem para a calçada, tanto mais completamente o espaço público é passível de apropriação pela casa" (SANTOS; VOGEL e MELLO, 1985, p. 54). E a principal regra que permite esse fluxo é o pertencer àquele círculo social de crianças.

O agrupamento das crianças que brincam na rua não delimita um "pedaço" (MAGNANI, 1996) na rua, como fazem o agrupamento de homens no entorno do bar. Mas, assim como eles, ao se sociarem, vão criando aos espaços outros significados de público, espaço aberto, e privado, espaço fechado. Ao fazer parte do grupo de crianças, cada uma delas tem livre acesso aos espaços apropriados pelas suas práticas de lazer. Portanto, essas crianças não se preocupam em avisar que estão chegando ou saindo, pela maneira como o grupo apropriou-se das práticas na casa de seus integrantes e na Rua Caieiras. No momento da brincadeira, não há diferença de limite e fronteiras dos espaços.

Entendemos que não formaram um "pedaço” (MAGNANI, 1996) delas na rua, pois esse agrupamento brinca em diferentes pontos, mas é possível compreender que formaram um "trajeto" (MAGNANI, 1996). Elas usualmente ficam em três casas, sentam-se na calçada em frente às mesmas, brincam na rua perto ao bar, vão ao pasto soltar pipa e ao loteamento jogar bola. Esse é o trajeto rotineiro delas e os pontos em que cotidianamente se encontram. 
A sociação dessas crianças neste círculo social permite, pela "experiência da rua" (MAGNANI, 1993), que as mesmas se apropriem do aprendizado fruto do envolvimento com o coletivo e da fruição do lazer. As práticas são transformadas cotidianamente pela própria experimentação, sendo notório o caráter criativo das práticas de lazer desse círculo social. A cada dia, éramos surpreendidos com uma novidade que, muitas vezes, foi influenciada pelos condicionantes das práticas.

Em dias muito quentes, por exemplo, as crianças deixavam de brincar de correr e ficavam na calçada jogando cartas e conversando. Decorrente da dificuldade de jogar bola na rua de paralelepípedo, o grupo mudou o jogo para as ruas novas, largas e com pouco movimento de carros no espaço do novo loteamento. A reinvenção de novas formas de brincar pode ser vista na seguinte narração do encontro do grupo de crianças, que foi relatada após a estiagem da chuva:

\begin{abstract}
Um pouco depois de a chuva cessar, o grupo de crianças que estava na calçada se dividiu. Os meninos se reuniram, eram 7 meninos, para jogar bola, e as meninas, que estavam com eles, entraram para casa. Mas, antes disso, ao discutir sobre o jogo, eles começaram a brincar de lançar os menores ao ar. Os dois maiores carregam os menores pelos braços e os lançam ao ar. Quando caem no chão, após o lançamento, cada menino começou a criar um movimento. Uns caiam e ficavam eretos, outros, agachados, os outros sentados. Alguns foram aprimorando a brincadeira e começaram a se jogar ao ar dando impulso e buscavam cada vez mais cair em pé e bem ereto. Teve um garoto que caiu de cara no chão. Ao verem que este não se machucou, todos os que estavam na brincadeira riram, inclusive o menino que caiu ao chão. Durante essa brincadeira, chegaram mais meninos. Eram 12 agora. Assim, pararam a brincadeira e foram ao loteamento jogar bola (DIÁRIO DE CAMPO).
\end{abstract}

Esse agrupamento é formado principalmente por meninos, entre 7 e 12 anos, que se encontram para empinar pipa, andar de bicicleta, jogar bola, ir ao Clube da Rhodia, frequentar o Centro Cultural Casarão do Barão. Em determinados momentos, têm certa permeabilidade em relação à participação de algumas meninas, bem como de meninos menores, ou interagem com jovens e adultos. Entretanto, isso ocorre de acordo com as 
regras do grupo que viabiliza essas interseções. Como observamos nos dias de chuva do relato acima, o encontro se deu na casa e, nessa, há meninas que se inserem e são inseridas por estarem no mesmo espaço.

Assim, os condicionantes climáticos atuam na sociabilidade entre as crianças e inferem nas práticas de lazer na rua. Além da chuva frequente, o vento também viabiliza a brincadeira de soltar pipa. Não só viabiliza como determina a época do ano e o horário dessa brincadeira e estabelece também relações de troca, evitação e conflito entre os moradores.

O soltar pipa tem horário certo, ao final da tarde quando o vento aparece com maior frequência. E, ao ocorrer o aumento do vento, os meninos surgem na rua em movimento similar ao bater o sinal da escola, com um desespero muito grande. Nesse momento, não enxergam as divisões dos lugares, as barreiras dos muros e da estrada. Reúnem-se nos espaços mais abertos e começam a brincadeira.

O lugar da pipa é o céu, poucas coisas impediriam essa ocupação. As pipas, ao serem erguidas, ultrapassam os muros dos condomínios e das propriedades privadas. As crianças e os jovens usam de espaços mais abertos, como a parte de cima da Vila Holândia, próximos às casas novas, área mais nobre que elas pouco frequentam (chamado de loteamento), e o gramado da propriedade privada da madeireira (chamado de pasto) (DIÁRIO DE CAMPO).

O empinar pipa mantém determinadas tradições próprias dessa prática. Ele envolve majoritariamente sujeitos do sexo masculino e com a faixa etária entre 6 a 20 anos de idade. As relações de poder no soltar pipa são bem evidentes e é caracterizada pelas diferenças etárias. Quanto mais velho, maior é seu poder nessa brincadeira. Os meninos maiores, até adultos, são aqueles que cortam as pipas dos menores e também ficavam com elas após o corte, mantendo uma hierarquia nesse jogo. Alguns, ao final da brincadeira, davam seu troféu, as pipas cortadas, aos menores que os idolatravam depois, mas sempre pegam a linha e a rabiola para usarem na próxima vez em que forem empinar pipa. O grupo de meninos ficava, na maioria das vezes, no pasto, já os jovens ficavam no loteamento. A escolha do local envolvia delimitar áreas em que não 
haveria problemas com a rede de luz, ou seja, espaços que permitem que as pipas subam sem barreiras.

A interação do agrupamento de meninos perpassa também interações com adultos que usam a rua. Pela apropriação da rua, as ações desses moradores permeiam a identificação simbólica da vida em comunidade. Suas relações de pertencimento com o lugar e suas práticas aproximam o grupo de meninos com os adultos, fortalecendo a sociabilidade na rua. Observando, nesse sentido, a troca entre eles.

Quando subiram, brincaram com o Zé, morador da casa XXX, caminhoneiro e pai de alguns meninos que faziam parte desse grupo. O Zé, que estava lavando seu caminhão, pegou a mangueira e jogou água nos meninos. Enquanto isso, os meninos gritavam: - Aqui, Zé! Aqui, Zé! Quando ele parou, os meninos pegaram a mangueira e ficavam se molhando no meio da rua, em frente à casa desse morador (DIÁRIO DE CAMPO).

Esse morador, que é pai de uns dos meninos, tem boa relação com as crianças que brincam na rua e com esse grupo de meninos. Quando ele está na rua cuidando do seu caminhão, sempre fica observando as crianças e os carros que passam rápido. De vez em quando, alerta algumas crianças para saírem da rua quando passavam carros e motos (DIÁRIO DE CAMPO).

Acompanhando o movimento desse grupo, começamos a entender porque certas crianças fazem parte dele e outras não. Era preciso pertencer às famílias que permitem às crianças circularem pela Vila Holândia, pois são elas que veem as práticas de lazer na rua como adequada e pertinente. Aquelas crianças que não fazem parte desse grupo pertencem a famílias que consideram a rua como lugar inseguro, ou seja, inadequado, (im) pertinente e (im) próprio para as crianças e para seus filhos.

Resolvemos ficar na Caieiras para conversar com algumas crianças que estavam na rua. Essas crianças não fazem parte do grupo que sempre víamos nas ruas. Eram três crianças a princípio, duas meninas e um menino. Uma das meninas estava sentada em uma cadeira em frente a sua casa, sendo este um dos motivos que mantivemos nossa conversa nesse local. Os três estudam na escola do bairro e são amigos da escola e da "rua". Eles também são amigos de outras crianças da vizinhança, mas costumam brincar mais entre eles. Esses não ficam brincando na rua. Segundo eles, às vezes ficam na rua. Já havíamos 
observado que, naquela casa, tinha uma criança, mas, sempre que a menina estava na rua, sua mãe ficava sentada na calçada também, observando-a. Não foram muitas vezes, mas quando as vimos, foi sob essa condição. Hoje mesmo, a mãe está em casa e as meninas na calçada, com o portão aberto(DIÁRIO DE CAMPO).

Ao conversar com as crianças, perguntamos onde costumam brincar quando estão fora da escola e por quê? Falaram que brincam pouco na rua porque a mãe não deixa ficar "muito" na rua e a mesma não deixa por ter medo. Ao falar desse medo, falaram dos carros que passam rapidamente pela rua. Elas falaram que, por isso, costumam brincar na casa dos amigos, sempre um vai à casa do outro e lá permanecem brincando. $\mathrm{O}$ amigo delas, morador da casa de frente a casa delas, segundo elas e ele também, falou que nunca brinca na rua porque a mãe tem medo da falta de segurança. Essas crianças se reúnem e brincam juntas, mas não na rua (DIÁRIO DE CAMPO).

No relato, é possível perceber que estas crianças não fazem parte do coletivo que se apropria desse lugar. No contexto de sociabilidade na rua, as crianças que brincam em casa são as outras. Elas também se agrupam no contexto da casa e da escola e, para tanto, suas famílias também têm interações, já que são envolvidas na privação da sociabilidade familiar da casa.

Além das outras e do grupo de meninos, havia também as meninas que moram ao final da Caieiras, próximo ao bar, que brincavam principalmente de andar de bicicleta. Elas usavam da rua e das calçadas, não viam e não se atentavam aos carros transitando e deixavam as bicicletas soltas pela rua, sem preocupação em as guardar nas suas casas. Estabeleciam trocas entre elas, pois algumas não tinham bicicleta. Para isso, as bicicletas eram divididas ou carregavam uns aos outros sem problemas com aproximações corporais, como duas crianças sentadas no mesmo banco, representando as possibilidades de resistência do brincar sobre os significados de transgressão nas práticas corporais.

Continuo na rua Caieiras e falamos agora do vazio que ocorre aos domingos no horário do almoço. É na particularidade da casa, com suas formas de sociabilidade familiar ou doméstica, que fomos compreender a especificidade deste dia. O tradicional almoço de domingo familiar ou em grupos de amigos é uma prática frequente nessa rua, 
sendo esse percebido como permanecendo na própria rua. Nesse dia, muitas pessoas circulavam pela rua para organizar esse momento, as panelas, as vozes, os cheiros, as músicas, tudo caracteriza essa prática desses moradores.

O encontro aos domingos tem, em algumas casas, a abertura do espaço para os vizinhos. Nele, os integrantes do almoço, pertencentes desse coletivo, entram e saem das casas sem a preocupação do limite entre a casa e a rua. Por essa sociabilidade que perpassa os vínculos familiares próprios do espaço privado da casa, é possível vê-lo como público para aqueles que o integram.

\begin{abstract}
As manifestações socioculturais características de um grupo e que servem para distingui-lo, em relação a quem é de fora e para seus próprios membros, sempre estão referidas a conceitos de "abertura" de espaços. Irão se dar em locais públicos ou naqueles que, por força de um uso especial, passarão a ser vistos "como se fossem públicos". Jogos, reuniões, festas, encontros, cerimônias e atividades assemelhadas que se oponham às ideias de privacidade e de intimidade, encontram na rua o seu lugar ideal. É aí que se deve estar o que é de todos, de modo que, quando se dão em locais fechados, fazem-nos sofrer uma transformação. Em contrapartida, quando são levadas à rua ações que tenham sentido particular e restrito, a via pública como que se "fecha" (VOGUE e MELLO, 1985, p. 13).
\end{abstract}

\title{
Quem Manda na Rua? Condicionantes das Práticas de Lazer
}

A princípio, foram as mudanças sociais e as transformações urbanas que chamaram a atenção como condicionante dos usos da rua: o entorno da Vila cercado por condomínios privados com suas estruturas de segurança privada, os problemas dos serviços públicos de transporte, as diferenças na pavimentação e na iluminação pública na Vila, a chegada dos novos moradores e suas relações com a chegada da insegurança nas ruas. Entretanto, cada vez que entrávamos na Vila, pelo olhar "de perto e de dentro", percebíamos que também havia formas tradicionais que condicionam os usos da rua para as práticas de lazer. 
A alteração climática, como as temperaturas baixas e muito altas, precipitações de chuvas contínuas e frequentes, curtas e fortes, a chegada do vento forte, as rotinas semanais do dia a dia, diferindo da noite para o dia, dos dias de semana para os finais de semana, feriado e férias atuam determinando as práticas de lazer. Nos dias chuvosos, percebíamos que a rua ficava vazia, as calçadas molhadas e sem moradores sobre as mesmas. Enquanto, nos dias de inverno, durante o dia, havia muitos moradores sobre as calçadas, tomando sol para se aquecerem. A chegada do período de ventos fortes, em junho, altera as brincadeiras do grupo de crianças que brincam na rua. Elas deixam a prática de jogar bola para ir empinar pipa, saindo da rua propriamente dita, ponto onde jogam bola, e se direcionam ao espaço do pasto, ponto em que soltam pipas.

A sociabilidade entre os moradores, estabelecida pela relação histórica e cultural, bem como as interações atuais de troca, evitação e conflito, determina também o porquê alguns moradores usam a rua e outros não. Ela, pela possibilidade de troca, interfere principalmente nas questões de segurança pública. Os moradores que se apropriam da rua e das práticas têm nela um lugar seguro, já os outros, decorrente da crescente reorganização urbana marcada pela mobilidade dos moradores e das práticas existentes no entorno do bar, consideraram a rua propícia para a violência urbana.

As próprias recordações das interações entre vizinhos decorrentes das festas na Vila que existiam antigamente repercutem no comportamento dos moradores que usam da rua atualmente, agregando o sentido de adequado e próprio ao uso desta para as práticas de lazer. Nesse sentido, a sociação entre esses moradores permite a perpetuação de geração em geração das interações na rua. Entretanto, também há sociações de moradores contrários a esse processo, como o agrupamento de idosas na Cerquilho, que não se apropria mais da rua, pois tem, nas formas como a rua está sendo apropriada, um significado maléfico à vida dos moradores da Vila. Assim, a interação entre moradores 
torna-se uma condicionante das formas de sociabilidade na rua e redefinem o cotidiano desta.

Em suma, categorizamos os condicionantes do uso da estrutura social da rua da seguinte forma: urbanização (infraestrutura de transporte público, asfaltamento da rua, iluminação pública, segurança pública); sociabilidade entre moradores (relações históricas e culturais, conflitos entre vizinhos e as trocas entre os vizinhos, precursora de segurança e insegurança); condições climáticas (chuva, vento, frio, sol, calor); calendário cristão (dias de semana, fins de semana, feriados, férias).

Existe uma grande tensão entre os condicionantes externos à Vila, frutos do processo de urbanização, e os condicionantes internos, principalmente a sociabilidade nas ruas entre os moradores. Essa tensão permite compreender as orientações de uso da rua para as práticas de lazer, ou seja, é ela quem manda na rua e consolida as regras para a apropriação do espaço e das práticas sociais. Mesmo assim, a presente vida associativa nas ruas da Vila Holândia, principalmente pelo uso para práticas de lazer e pela sociação em círculos sociais aqui descritos, permite definir a rua como espaço de resistência a fragmentação da urbanização em prol de uma vida comunitária.

As práticas de lazer na rua são uma possibilidade das formas de sociabilidade entre vizinhos, moradores, amigos e familiares. As presentes formas de sociação entre os moradores na rua configuram nas práticas de lazer a educação para o tempo livre. É na pedagogia da rua (SANTOS; VOGEL e MELLO 1985) que as regras são elaboradas, definidas e apropriadas em meio às diferentes relações entre os moradores estabelecendo formas de aprendizado na vida comunitária.

As formas de sociação que fluem nas ruas podem dar acesso aos moradores a outras práticas de lazer. Isso foi notado, pois são os grupos que se reúnem pelas relações de convívio na rua que vão apropriar dos espaços do Centro Cultural Casarão do Barão, 
do Clube da Rhodia, da Igreja e do bar. A sociação em grupos etários facilita a participação nas práticas de lazer em outros espaços do entorno da Vila Holândia.

A riqueza das experiências da rua, na Vila Holândia, permite tê-la como uma ilha rodeada de espaços que privatizam cada vez mais as relações sociais dos seus moradores, os condomínios. São eles, os moradores dos condomínios excluídos da vida comunitária, imersos nas relações neutras da evitação, sem qualquer tipo de conflito entre vizinhos e ausentes de trocas entre os moradores. E os moradores da Vila são incluídos na incumbência de reinventar suas regras e estabelecer formas de sociabilidade pela fruição do lazer na rua.

Assim, não são apenas as formas de segurança privada, a construção de equipamentos de lazer e o aumento de acessibilidade aos serviços públicos que irão garantir aos moradores da Vila Holândia condições de subverter a lógica da urbanização das cidades. Serão estes emaranhados nos condicionantes externos e internos de suas formas significativas de sociação e apropriação das práticas de lazer no tempo livre que vão criar e recriar a vida comunitária. É no tecido social pelas relações de conflitos, trocas e até a evitação entre os moradores que ocorre a formação da educação para o tempo livre e a definição do seu lugar de usufruto. Podem existir as transformações urbanas, mas não cabe apenas relegar a elas e ao poder público a resolução dos problemas sociais próprios da vida em comunidade.

\section{REFERÊNCIAS}

AZEVEDO, Amailton Magno Guillu; SILVA, Salloma Salomão Jovino. Os sons que vêm da rua. In: ANDRADE, E. N. A. Rap e educação, Rap é educação. São Paulo: Summus, 1999. Cap. 5, p. 65-82.

CERTEAU, Michel de. A invenção do cotidiano. Artes de fazer. 21. ed. Petrópolis: Editora Vozes, 2014. 316 p.

A invenção do cotidiano. 9. ed. Petrópolis: Vozes, 2009. 
DaMATTA, Roberto. A casa \& a rua: Espaço, cidadania, mulher e morte no Brasil. 4. ed. Rio de Janeiro: Guanabara Koogan, 1991.

DUPAS, Gilberto. Tensões contemporâneas entre público e privado. Cadernos de Pesquisa, v. 35, n. 124, p. 33-42, jan./abr. 2005.

FORTUNA, C. (Org.). Cidade, Cultura e Globalização: ensaios de sociologia. Celta: Oeiras, 1997.

FORTUNA, Carlos. "In Praise of other views: The world of cities and the social sciences" Iberoamericana, Berlim, n. 45, p. 137 -153, 2012.

LAVE, Jean e WENGER, E. Siruared learning. Legitimate peripheral participarion. Cambridge, England: Cambridge Universiry Press, 1991.

LEFEBVRE, Henry. A revolução urbana. Belo Horizonte: UFMG, 1999. 176 p.

A revolução urbana. Belo Horizonte: UFMG, 2008.

MAGNANI, José Guilherme. A rua e a evolução da sociabilidade. Cadernos de História de São Paulo 2, jan/dez, Museu Paulista- USP, 1993.

. Da periferia ao Centro: trajetórias de pesquisa em Antropologia Urbana. São

Paulo: Terceiro Nome, 2012.

MAGNANI, José Guilherme Cantor. Quando o campo é a cidade: fazendo antropologia na metrópole. In: . e TORRES, Lilian Lucca (Org.). Na metrópole: textos de antropologia urbana. EDUSP, São Paulo, 1996.

. De perto e de dentro: notas para uma etnografia urbana. Revista Brasileira de Ciências Sociais, São Paulo, v. 17, n. 49, p.11-29, 2002.

MALINOVSKI, Bronislaw. Os argonautas do Pacífico Ocidental. In: Ethnologia, n.s., $n^{\circ}$ 6-8, 1997, p. 17-37.

POL, Enric. La apropriación del espacio. In: IÑIGUEZ e POL (Org.) Cognición, representación y apropiación del espacio. Barcelona: Universitat de Barcelona Publicacions, 1996.

; MORANTA, Tomeu. La apropiación del espacio: una propuesta teórica para comprender la vinculación entre las personas y los lugares. Anuario de Psicología, v. 36, n. 3, p. 281-297, 2005.

SANTOS, C. N. F.; VOGEL, A.; MELLO, M. A. da S. Quando a rua vira casa. São Paulo: Projeto Arquitetos Associados, 1985.

SANTOS, M. Técnica, espaço, tempo: globalização e meio técnico científico informal. 5. ed. São Paulo: EDUSP, 2008. . O espaço do cidadão. 4. ed. São Paulo: Nove, 1998. 
SIMMEL, Georg. Sociología, 2: Estudios sobre las formas de socialización. Madrid: Alianza Editorial: 1986.

SMOLKA, Ana Luiza Bustamante. O (im) próprio e o (im) pertinente, na apropriação das práticas corporais das práticas sociais. Cadernos Cedes, v.20, n. 50, abril, 2000.

\section{Endereço das Autoras:}

Carolina Gontijo Lopes

Emmastrasse 17

50937 Köln

Deutschland

Endereço Eletrônico: carolminasfef@yahoo.com.br

Silvia Cristina F. Amaral

Departamento de Educação Física e Humanidades

Faculdade de Educação Física, Caixa Postal 6134

Universidade Estadual de Campinas - UNICAMP

Rua Érico Veríssimo, no 701 - Cidade Universitária

Campinas - SP - 13083-851

Endereço Eletrônico: scfa@fef.unicamp.br 